\section{Autoantikörper gegen C3-Konvertase}

W. Stöcker

Euroimmun Medizinische Labordiagnostika AG, Lübeck, Deutschland

Synonym(e) C3-Konvertase-Antikörper; Anti-C3bBb-Antikörper; Autoantikörper gegen C3-Nephritisfaktor

Englischer Begriff C3 nephritic factor

Definition Es handelt sich um Autoantikörper gegen das auf dem alternativen Komplementaktivierungsweg gebildete Enzym C3-Konvertase (C3bBb).

Funktion - Pathophysiologie Autoantikörper gegen die C3-Konvertase stabilisieren das Enzym C3-Konvertase und behindern dessen ständige physiologische Inaktivierung durch das Kontrollprotein Faktor $\mathrm{H}$, was sich im gesteigerten Verbrauch an Komplementfaktor C3 widerspiegelt.

Untersuchungsmaterial Serum, EDTA-Plasma.

Probenstabilität Autoantikörper sind bei $+4{ }^{\circ} \mathrm{C}$ bis zu 2 Wochen lang beständig, bei $-20^{\circ} \mathrm{C}$ über Monate und Jahre hinweg.

Analytik Für die Analyse des C3-Nephritisfaktors eignen sich mehrere Testprinzipien:

- Ein funktioneller Test, der auf der Komplement-vermittelten Lyse von Indikatorzellen beruht. Der Test ist so eingestellt, dass in einem Testsystem enthaltenes $\mathrm{C} 3 \mathrm{bBb}$ nur dann ausreichend aktiv ist und eine Lyse hervorruft, wenn es durch in der Probe enthaltene Autoantikörper gegen die C3-Konvertase stabilisiert wird.
- Eine $>$ Immunfixation-Elektrophorese, bei der eine definierte Menge C3 der Spaltung durch C3-Konvertase unterworfen wird. Setzt man vorher Patientenserum mit Autoantikörpern gegen die C3-Konvertase hinzu, erhöht sich durch die stabilisierende Wirkung des Autoantikörpers die Menge an gebildetem C $3 \mathrm{~b}$. Ergibt sich bei einem Vergleich zweier Ansätze, einmal mit und einmal ohne Zusatz von Patientenserum, ein signifikanter Unterschied, ist die Präsenz des Autoantikörpers erwiesen.

- Ein \Enzyme-linked Immunosorbent Assay mit Festphasen-gebundenem $\mathrm{C} 3 \mathrm{bBb}$ als Antigen.

Referenzbereich - Erwachsene Nicht nachweisbar.

Referenzbereich - Kinder Nicht nachweisbar.

Indikation Klinische Manifestationsformen sind die membranproliferative Glomerulonephritis sowie eine partielle Lipodystrophie, bei der das Fettgewebe der Subkutis zerstört wird.

Interpretation Zur diagnostischen Abklärung der Fälle mit membranproliferativer Glomerulonephritis oder Lipodystrophie wird parallel zur Diagnostik der Autoantikörper gegen C3-Konvertase die Komplement-C3-Konzentration gemessen. Falls funktionell wirksame Antikörper gegen C3-Konvertase vorliegen, wird man eine niedrige $\mathrm{C} 3$-Konzentration vorfinden, da die Hemmung des C3-Abbaus gestört ist.

\section{Literatur}

Jelezarova E, Schlumberger M, Sadallah S et al (2001) A C3 convertase assay for nephritic factor functional activity. J Immunol Methods 251:45-52 